\title{
RNA Interference Highlights the Role of CCaMK in Dissemination of Endosymbionts in the Aeschynomeneae Legume Arachis
}

\author{
Senjuti Sinharoy and Maitrayee DasGupta \\ Department of Biochemistry, Calcutta University, 35 Ballygaunge Circular Road, Calcutta 700019, India
}

Submitted 27 April 2009. Accepted 1 July 2009.

\begin{abstract}
In legume-rhizobia symbiosis, $\mathrm{Ca}^{2+} /$ calmodulin-dependent protein kinase (CCaMK) is essential for rhizobial invasion through infection threads in the epidermis and nodule organogenesis in the cortex. Though $\mathrm{CCaMK}$ is actively transcribed in the infected zone of nodules, its role in the later stages of nodule development remain elusive because of the epidermal arrest of "loss-of-function" mutants. In Aeschynomeneae legumes such as Arachis hypogea, rhizobia directly access the cortex, where nodule organogenesis as well as endosymbiont dissemination take place by multiplication of infected cortical cells. We characterized CCaMK (GI:195542474) from A. hypogea and downregulated the kinase through RNA interference (RNAi) to understand its role during organogenesis of its characteristic aeschynomenoid nodules. In CCaMK downregulated plants, the inception of nodules was delayed by approximately 4 weeks and nodulation capacity was decreased $(>90 \%)$. The infected zones of the RNA interference nodules were scattered with uninfected or binucleated cells as opposed to the homogeneous infection zone in empty-vector-transformed nodules. Symbiosomes in RNAi nodules were pleomorphic with diverse geometrical shapes or arrested during division in the final stages of their fission as opposed to uniform-sized, spherical symbiosomes in empty-vector-transformed nodules. Together, our results reveal CCaMK to be essential for development of functional aeschynomenoid nodules, with a critical role in rhizobial dissemination during nodule organogenesis.
\end{abstract}

Nitrogen-fixing root nodule symbiosis (RNS) in plants is restricted to a monophyletic group of four angiosperm orders (Kistner and Parniske 2002). RNS occurs in two major forms: legume-rhizobia and actinorhizal symbiosis. The legume-rhizobia association has received more attention because several important crop plants are supported by this association (Doyle and Luckow 2003). Rhizobial invasion broadly follows two different strategies, by either "root-hair entry" through intracellular infection threads (IT) or "crack entry" at the lateral root base in an intercellular manner (Oldroyd and Downie 2008). Invasion through IT is adapted mostly by temperate legumes (e.g., Vicia, Trifolium, Pisum, and Medicago spp.) whereas crack entry is observed in some subtropical legumes

Corresponding author: M. DasGupta; E-mail: maitrayee_d@ @otmail.com

* The $e$-Xtra logo stands for "electronic extra" and indicates that seven supplemental figures are published online and that Figures 1, 3, 4, 5, and 6 are published in color online. (e.g., Aeschynomene, Stylosanthes, and Arachis spp.) (Gage 2004; Oldroyd and Downie 2004). Some species can switch in between root-hair entry and crack entry depending on environmental cues (e.g., Sesbania rostrata [Goormachtig et al. 2004] and Lotus uliginosus [James and Sprent 1999]), though deeper invasion in these legumes for cortical colonization and rhizobial dissemination involves formation of transcellular IT. For the majority of the crack-entry legumes, which account for approximately $25 \%$ of all legume genera, transcellular IT are never observed during epidermal or cortical processes. These legumes remain much less investigated and may be referred to as non-IT legumes (Sprent 2007). Legumes belonging to the Aeschynomeneae or Dalbergieae tribes of the subfamily Papilionoideae are non-IT legumes. In these legumes, rhizobia directly invade cortical cells and their dissemination takes place by repeated division of the infected cells to give rise to their characteristic aeschynomenoid nodules, with no uninfected interstitial cells interspersed in the infected zone (Chandler 1978; Alazar and Duhoux 1990; Boogerd and Rossum 1997; Klitgaard and Lavin 2005 ).

Regardless of whether the initial entry is through root hairs or epidermal cracks, in almost all legumes, nod factors secreted by rhizobia play a central role in the molecular dialogue that is involved in the establishment of RNS (Oldroyd and Downie 2008). Nod factors are likely to be recognized through receptorlike kinases such as $L$. japonicus-nod factor receptor $(\mathrm{Lj}-$ NFR)1/Mt-LYK3 (M. truncatula-lysM domain-containing receptor-like kinase) and Lj-NFR5/Mt-NFP (M. truncatula-nod factor perception) (Limpens et al. 2003; Madsen et al. 2003; Radutoiu et al. 2003; Arrighi et al. 2006; Smit et al. 2007). Downstream to these receptor kinases is the "Sym pathway," which consists of host-encoded factors and is required for establishment of both RNS and arbuscular mycorrhiza (AM) (Catoira et al. 2000; Kistner et al. 2005). These factors include the NORK extracellular sequence-like domain containing leucinerich repeat receptor kinase Lj-SYMRK/Mt-DMI2 (L. japonicus symbiosis receptor-like kinase and $M$. truncatula doesn't make infection) (Endre et al. 2002; Stracke et al. 2002), the predicted ion-channel proteins Lj-CASTOR and Lj-POLLUX/Mt-DMI1 (Ane et al. 2004; Imaizumi-Anraku et al. 2005), the nucleoporins Lj-NUP85 and Lj-NUP133 (Kanamori et al. 2006; Saito et al. 2007), the $L$. japonicus $\mathrm{Ca}^{2+} /$ calmodulin-dependent protein kinase CCaMK/Mt-DMI3 (Levy et al. 2004; Mitra et al. 2004; Tirichine et al. 2006a and b), and the M. truncatula DMI3 interacting protein Lj-CYCLOPS/Mt-IPD3 (Messinese et al. 2007; Chen et al. 2008; Yano et al. 2008). In addition, calcium spikes are elicited within the Sym pathway with characteristic waveforms associated with RNS and AM (Ehrhardt et al. 1996; Kosuta et al. 2008). CCaMK is believed to be involved in the 
recognition and interpretation of these spikes that are specific to each symbiosis (Wais et al. 2000; Oldroyd and Downie 2004). Nodulation-specific transcription factors, such as MtNSP1 and MtNSP2 (M. truncatula nodulation-signaling pathways), MtERF1 (required for nodulation), and Lj-NIN (nodule inception), function downstream of the Sym pathway and are involved in transcriptional reprogramming for initiation of RNS (Schauser et al. 1999; Kalo et al. 2005; Smit et al. 2005; Middleton et al. 2007).

Central to the regulation of CCaMK is an autoinhibitory domain within the calcium/calmodulin-binding domain, deregulation of which leads to autonodulation in the absence of bacterial elicitation (Gleason et al. 2006; Tirichine et al. 2006b). This indicated that CCaMK is essential for coordination between rhizobial invasion through IT in the epidermis and the development of nodule primordia in the cortex (Oldroyd and Downie 2008). CYCLOPS, a substrate for $\mathrm{CCaMK}$, is specifically required for infection, whereas organogenesis is envisaged to require additional substrates (Yano et al. 2008). Because of the epidermal arrest of loss-of-function mutants, a clear picture of the role of CCaMK in the later stages of nodule development remain elusive. Non-IT legumes breach the epidermis and allow one to check the role of factors involved in nod-factor signaling in cortical processes. We used the non-IT legume Arachis hypogea for investigating the role of CCaMK during nodule development. A. hypogea belongs to the Aeschynomeneae or Dalbergieae tribe, which is relatively basal in its divergence within the Papilionoids (Hougaard et al. 2008; Bertioli et al. 2009). Nod factor has been identified from Arachis sp.-specific Bradyrhizobium spp. (Taurian et al. 2008) but it is not yet known whether Arachis spp., like the other members of the aeschynomenae tribe, can undergo successful nodulation in the absence of nod factor (Gillette and Elkan 1996; Giraud et al. 2007). The results presented here show that CCaMK, a member of the nod-factor signaling cascade, is expressed in A. hypogea roots and nodules. Through RNA interference (RNAi)-mediated knockdown of A. hypogea CCaMK (hereafter called AhCCaMK), we demonstrate that the kinase has essential roles in dissemination of the endosymbionts during the development of its characteristic aeschynomenoid nodules.

\section{RESULTS}

\section{Characteristics of $A h C C a M K$.}

AhCCaMK was isolated by amplification of root cDNA using a degenerate priming approach based on legume CCaMK sequences. AhCCaMK shows the highest homology with its predicted orthologue in S. rostrata, with $89 \%$ amino acid identity (Fig. 1A). It clusters together with CCaMK from other legume species in a phylogenetic distance tree but is placed nearest to the point of divergence of CCaMK from legumes and nonlegumes (Fig. 1B). Maximum sequence variability was noted in between $\beta$ strand $2(\beta 2)$ and helix $C(\alpha C)$ of the catalytic domain (Supplementary Fig. 1). Structural alignment of homology models reveals that the variable region between $\beta 2$ and $\beta 3$, with the exception of Pisum sativum CCaMK, is superimposable (Fig. 1C). In contrast, the variable region between $\beta 3$ and $\alpha \mathrm{C}$ protrudes as a loop from the $\mathrm{N}$-terminal domain of the superimposed core structure of the kinase, with noticeable differences in their predicted structure. Although, in nonlegumes such as Lilium longiflorum and Oryza sativa, this loop appeared extended and unstructured, with a propensity of forming $\beta$-sheets, in legumes such as $S$. rostrata, $P$. sativum, Medicago truncatula, and Lotus japonicus, the loop appeared to from perfect helices. In A. hypogea, the loop appeared unstructured, with a single helical turn, which made
AhCCaMK structurally closer to $\mathrm{CCaMK}$ from nonlegumes and is consistent with its position being near the point of divergence of CCaMK from legumes and nonlegumes. The functional importance of this loop remains unknown but such loops in the same structural position have been earlier designated as a fingerprint feature of members of the family of death-associated protein kinases (DAPK) as well as in certain members of the CDPK family (Tereshko et al. 2001; Raichaudhuri et al. 2006).

Quantitative reverse-transcription polymerase chain reaction (qRT-PCR) was performed to determine the steady-state levels of AhCCaMK transcripts in different organs of A. hypogea (Fig. 2). The expression of AhCCaMK was highest in infected or uninfected roots and in nodules, which is similar to the expression profiles of CCaMK in other legumes (Levy et al. 2004). In addition, the expression of AhCCaMK was also high in pegs (reproductive organ with positive geotropism) and immature pods. This appears to be consistent with the fact that A. hypogea pegs penetrate into the soil for developing pods and association of AM fungi have been reported to occur in pegs of Arachis spp. (Graw and Rehm 1977). We analyzed the subcellular localization of AhCCaMK in A. hypogea hairy roots by using $35 \mathrm{~S}$ promoter-driven green fluorescent protein (GFP)-CCaMK in a fusion construct (p35S::GFP-AhCCaMK). AhCCaMK localized into the nucleus in A. hypogea root cells (Fig. 3), which is in accordance with earlier reports where CCaMK in $M$. truncatula have been shown to localize into the nucleus (Kalo et al. 2005; Smit et al. 2005). Green signals associated with the cell wall are due to autofluorescence in the green channel, as was also observed in wild-type cells (data not shown).

\section{Knockdown of AhCCaMK affects nodulation in A. hypogea.}

AhCCaMK expression was reduced in A. hypogea roots by Agrobacterium rhizogenes-mediated introduction (Sinharoy et al. 2009) of two independent RNAi-constructs i) 54 to 565 nucleotides (nt) encompassing the $\beta 2-\alpha \mathrm{C}$ variable loop region of the kinase domain and ii) 1,017 to 1,514 nt of the visinindomain (Supplementary Fig. 2A). As a control, roots transformed with empty vector (control) lacking the Arachis hypogea CCaMK-RNAi cassette were analyzed. AhCCaMK expression was tested by qRT-PCR in transformed roots of both categories of AhCCaMK-RNAi roots. A 52 to $76 \%$ reduction of AhCCaMK mRNA levels was observed in RNAi roots compared with control-transformed roots.

Composite plants were inoculated with Bradyrhizobium strain NC92 and nodulation was scored for 10 weeks after inoculation (WAI) in transformed roots selected by their GFP expression (Fig. 4A,B; Table 1). In control-transformed roots, nodule development was noticed within 1 to 2 WAI whereas such structures first appeared in RNAi-transformed roots only 6 WAI (Table 1). Within 4 to 5 WAI, the control-transformed roots were almost saturated with nitrogen-fixing spherical nodules (Table 1). On the other hand, concomitant with the emergence of the nodules at 6 to $7 \mathrm{WAI}$, the composite plants with RNAi roots lost vigor and almost $50 \%$ of the plants died before nodulation was scored at approximately 9 to 10 WAI in plants that survived. These plants, except for having lesser growth, looked healthy (Supplementary Fig. 3); however, there was approximately $90 \%$ reduction in the number of nodules in their RNAi roots (Table 1). Whereas 1 to 2 nodules developed per RNAi root, on the same plant, roots that were not transformed developed 10 to 15 nodules (Fig. 4A and B). Such delay and decrease in the number of nodules in the AhCCaMK downregulated roots is in accordance with the role of CCaMK in development of RNS that has been reported earlier (Levy et 
al. 2004; Gleason et al. 2006; Godfroy et al. 2006; Banba et al. 2008).

Acetylene-reduction activity in the nodulated RNAi roots was very low compared with its control-transformed counterpart or the wild type, indicating reduced nitrogenase activity in the RNAi nodules (Fig. 4C). The control-transformed nodules resembled the wild-type nodules in having a red homogeneous interior (Supplementary Fig. 4A and B). The interior of the transgenic nodules showed green fluorescence from the cotransformation marker GFP though the level of fluorescence was very low in the central infected zone. We previously described that $35 \mathrm{~S}$-driven $\beta$-glucuronidase expression was strong in the invaded region of the nodule, indicating that the low fluorescence of GFP was not due to silencing of the promoter (Sinharoy et al. 2009). Rather, it indicated quenching of the GFP fluorescence in the invaded region, as reported earlier in M. truncatula nodules (Auriac and Timmers 2007). The RNAi nodules had either a pink mosaic or white interior and had scattered zones of strong autofluorescence. Such increase in autofluorescence has been noted in symbiotic mutant (nip) of M. truncatula and is thought to be due to a possible induction of defense response (Veereshlingam et al. 2004).
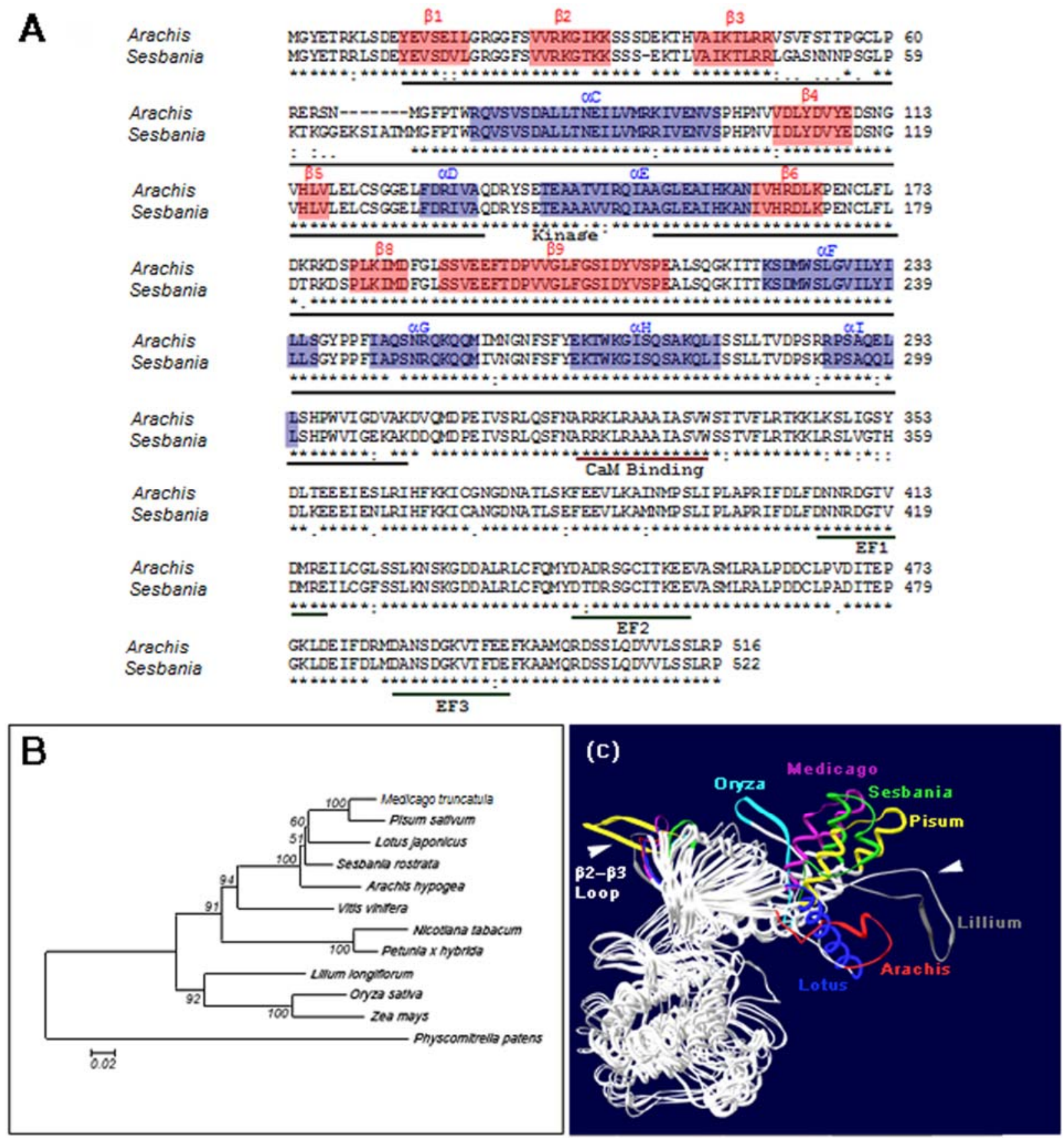

Fig. 1. $\mathrm{Ca}^{2+} /$ calmodulin-dependent protein kinase (CCaMK) of Arachis hypogea. A, Alignment of CCaMK from Arachis hypogea and Sesbania rostrata. Sequences were aligned using ClustalW. Identical amino acids are indicated by asterisks and similar amino acids are marked with dots and colons. Catalytic domain, calmodulin-binding domain, and EF-hands of visinin-like domain are underlined on the basis of in silico predictions. Conserved $\alpha$-helix and $\beta$-sheet in the kinase domain are highlighted by blue and red colors, respectively. B, Position of A. hypogea CCaMK in a distance tree predicted on the basis of available CCaMK protein sequences. Tree was generated based on a CLUSTALW alignment. Numbers above the branches represent the percentages of 1,000 bootstrap replications. C, Structural alignment of homology models of CCaMK. Ribbon model of structures generated by using kinase domain of A. hypogea, Medicago truncatula, Lotus japonicus, Pisum sativum, S. rostrata, Lilium longiflorum, and Oryza sativa are aligned. Residues between $\beta 2$ and $\beta 3$ and $\beta 3$ and $\alpha \mathrm{C}$ of all kinases are highlighted. Color coding: Arachis, red; Medicago, purple; Lotus, dark blue; Sesbania, green; Pisum, yellow; Lilium, gray; and Oryza, light blue. 
A feature associated with hairy roots of A. hypogea is generation of nodular roots, which are unbranched roots exhibiting negative geotropism growing at the nodule apex (Akasaka et al. 1998; Sinharoy et al. 2009). Although only 2 to $3 \%$ of the nodules contained nodular roots in almost all the control composite plants, there was approximately $40 \%$ nodules with nodular-roots in approximately $50 \%(14 / 25)$ of the RNAi composite plants (Table 1). In RNAi nodules, the nodular roots behaved like adventitious roots, exhibiting normal growth and branching (Fig. 4D and E). The interiors of nodules containing nodular roots were noted to be pink with relatively homogeneous GFP fluorescence. Consistent with the pink and homogeneous interior of the nodules with apical roots, there was a small increase of acetylene reduction activity in roots having such nodules (Fig. 4C), the significance of which is not understood.

\section{Knockdown of AhCCaMK affects} dissemination of the symbiont during aeschynomenoid nodule development.

In A. hypogea, rhizobia directly invade root cortical cells and their dissemination within the nodule is believed to take

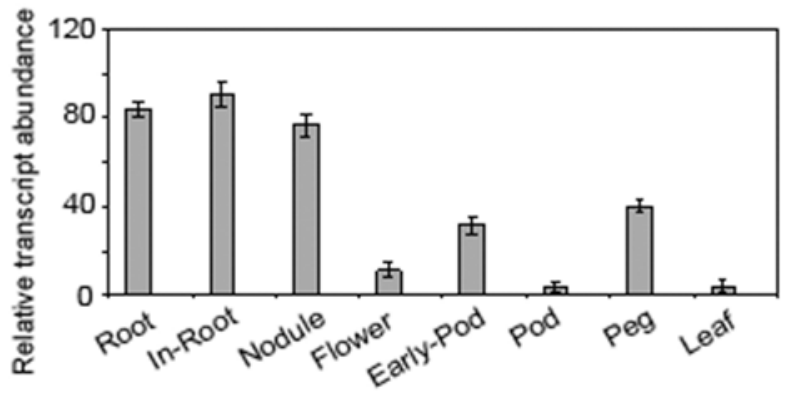

Fig. 2. Expression of Arachis hypogea $\mathrm{Ca}^{2+} /$ calmodulin-dependent protein kinase $(\mathrm{AhCCaMK})$ in different tissues of Arachis hypogea. Relative transcript abundance of AhCCaMK in uninfected roots, 3-day infected roots (Inroots), nodules (3 weeks after infection), flowers, pods, pegs, and leaves. Relative transcript abundance was determined by quantitative reverse-transcription polymerase chain reaction and normalized against $A$. hypogea actin (EU982407), which is constitutively expressed in all tissues tested. Error bars represent standard deviations from three independent experiments.
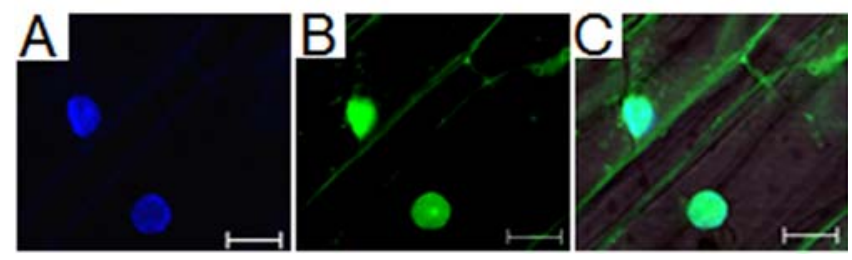

Fig. 3. Subcellular localization of Arachis hypogea $\mathrm{Ca}^{2+} /$ calmodulindependent protein kinase (AhCCaMK) by confocal microscopy. Green fluorescent protein (GFP)-AhCCaMK localizes in the nucleus of root epidermal cells. A, 4',6-Diamidino-2-phenylindole and $\mathbf{B}$, GFP signals are shown in two different channels and $\mathbf{C}$, in the third channel, signals are merged with a bright-field image. Bars: $10 \mu \mathrm{m}$. place by repeated division of the infected cells, giving rise to aeschynomenoid nodules (Alazar and Duhoux 1990; Boogerd and Rossum 1997; Klitgaard and Lavin 2005). In the later phases of nodule development, the rod-shaped rhizobia synchronously differentiates itself into bacteroids in spherical symbiosomes (Sen et al. 1986; Bal et al. 1989; Boogerd and Rossum 1997). To avoid confusion, we followed the nomenclature in Arachis literature and have referred to the rodshaped form as rhizobia and the spherical form as symbiosomes (Boogerd and Rossum 1997). The effect of downregulation of AhCCaMK was studied in both early and mature nodules. To visualize rhizobia inside the nodules, a mixture of two cell-permeable fluorescent dyes, SYTO9 and PI, was used (Partida-Martinez and Hertweck 2005). Both dyes are nucleicacid intercalaters but, due to higher permeability, SYTO9 usually stains live cells. On the other hand, PI being a stronger intercalater, it replaces SYTO9 in dead cells. These two dyes differentially stained the interior (PI) and the peripheral components (SYTO9) of the symbiosomes when cryosections of

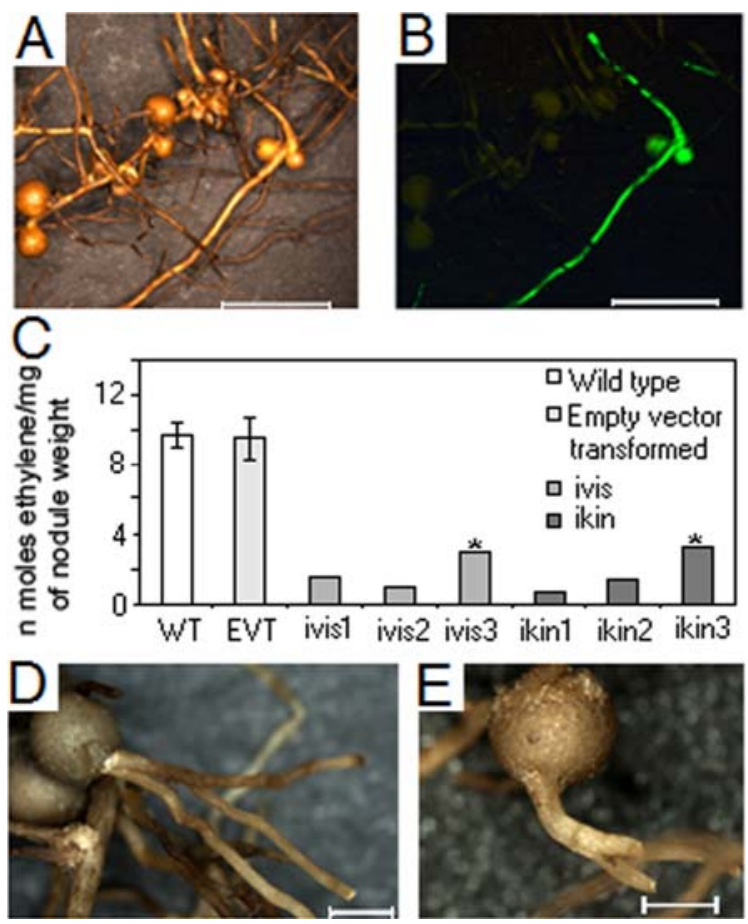

Fig. 4. Characteristics of RNA interference (RNAi) nodules. Nodulated RNAi roots observed under $\mathbf{A}$, bright-field and $\mathbf{B}$, blue-light excitation to identify hairy roots that were green fluorescent protein positive and distinguish them from the noncotransformed roots. C, Acetylene reduction assay of six independent RNAi roots (10 weeks after inoculation [WAI], three from ikin three ivis). As reference, the average of acetylene reduction by five wildtype and five control-transformed roots (4 WAI) is shown; * indicates roots having nodules with nodular roots. D and E, RNAi nodules showing adventitious root formation from nodule apex. Bars: A and B, $5 \mathrm{~mm}$; D and E, $1 \mathrm{~mm}$.

Table 1. Nodulation frequencies of transformed Arachis hypogea roots ${ }^{\mathrm{a}}$

\begin{tabular}{|c|c|c|c|c|c|c|c|c|}
\hline \multirow[b]{2}{*}{ WAI } & \multicolumn{2}{|c|}{$\begin{array}{l}\text { Fraction of plants with } \\
\text { transformed nodule }\end{array}$} & \multicolumn{2}{|c|}{$\begin{array}{c}\text { Transformed nodules } \\
\text { per plant }\end{array}$} & \multicolumn{2}{|c|}{$\begin{array}{c}\text { Fraction of plants having } \\
\text { nodular root }\end{array}$} & \multicolumn{2}{|c|}{$\begin{array}{c}\text { Nodular root containing } \\
\text { nodules per plant }\end{array}$} \\
\hline & Empty vector & RNAi & Empty vector & RNAi & Empty vector & RNAi & Empty vector & RNAi \\
\hline 1 to 2 & $18 / 25$ & $0 / 25$ & $2 \pm 2$ & 0 & $0 / 18$ & 0 & 0 & 0 \\
\hline 2 to 3 & $25 / 25$ & $0 / 25$ & $10 \pm 4$ & 0 & $0 / 25$ & 0 & 0 & 0 \\
\hline 4 to 5 & $25 / 25$ & $0 / 25$ & $60 \pm 10$ & 0 & $6 / 25$ & 0 & $1 \pm 1$ & 0 \\
\hline 6 to 7 & $25 / 25$ & $38 / 50$ & $118 \pm 26$ & $5 \pm 3$ & $14 / 25$ & $0 / 38$ & $3 \pm 2$ & 0 \\
\hline 8 to 10 & $25 / 25$ & $21 / 25$ & $118 \pm 26$ & $8 \pm 5$ & $23 / 25$ & $13 / 21$ & $3 \pm 2$ & $3 \pm 2$ \\
\hline
\end{tabular}

${ }^{a}$ At various timepoints following infection, indicated number of plants were harvested and nodulation was scored. WAI $=$ weeks after infection and RNAi $=$ RNA interference. 
mature nodules were analyzed (Sinharoy et al. 2009). In contrast, in paraffin sections, both dyes equally stained the nucleicacid components in the symbiosome interior (Supplementary Fig. 5). We reasoned that the dehydrating steps involved in preparing the paraffin sections led to the alteration in membrane properties, allowing both SYTO9 and PI to stain the nucleic acid in the interior. We have used the combination of these two dyes as a useful tool for studying the cryosections of nodules in our investigations. Also, because the fluorescence originating from our cotransformation marker GFP was low in the invaded region of the nodules and could only be observed under high laser power, it never interfered in our analysis using SYTO9 (Sinharoy et al. 2009).

Investigations were conducted on early nodules of similar size (approximately 0.5 to $0.6 \mathrm{~mm}$ in diameter) collected from control and RNAi-transformed roots at 2 and 6 WAI, respectively. At early stages in control-transformed as well as wildtype nodules, the rod-shaped rhizobia appeared green by selective uptake of the SYTO9 dye (Fig. 5A; Supplementary Fig. $6 \mathrm{~A})$. The infected zone in these nodules showed their aeschynomenoid arrangement, where infected cells were not interspersed with uninfected cells and the rhizobia were evenly distributed in the infected cell cytoplasm. In RNAi nodules, the rhizobia stained yellow in several infected cells due to uptake of both SYTO9 and PI, possibly due to alteration in permeability of the peribacteroid or the rhizobial membrane (Fig. 5B). Also, the RNAi nodules have empty and uninfected cells scattered in the infected zone, which is in contrast to homogeneously infected cells in the interior of the control-transformed and wild-type nodules. We found that the infected cells in RNAi nodules were temporarily arrested in a stage where rhizobia, instead of being evenly distributed in the cytoplasm, appeared entrapped and clustered around the nucleus (Fig. 5B and $\mathrm{C}$ ). Together, these observations suggest that, in AhCCaMK-downregulated plants, the infected cell division was both delayed and error prone, which led to the observed asymmetric partitioning of the rhizobia and, eventually, uneven dissemination of the symbiont in the nodule.

Nodules (approximately $2 \mathrm{~mm}$ in diameter) were collected from control and RNAi-transformed roots at 4 and $10 \mathrm{WAI}$, respectively, to investigate the effect of AhCCaMK downregulation in their mature form. At 4 WAI, the invaded zones in control-transformed and wild-type nodules were homogeneously infected, where all cells were uniformly packed with tightly arranged spherical symbiosomes of 2.5 to $3 \mu \mathrm{m}$ diameter (Fig. 5D and G). In contrast, the infected zone of RNAi nodules at 10 WAI was scattered, with pockets of cells containing few or no symbiosomes (Fig. 5E, F, H, and I; Supplementary Fig. 7A and B). Moreover, we could detect binucleated cells in almost all the 30 RNAi nodules that were investigated (Fig. 6A to C). These aberrations in the infected cells of the RNAi nodules and the improper partitioning and distribution of endosymbionts in them appears to have originated from error-prone divisions of the infected cells in the early stages of nodule development. In both control-transformed and wildtype nodules, PI and SYTO9 differentially stained the symbiosome interior (PI) and the peripheral components (SYTO9), giving them a distinctive "green ring red dot" signature appearance. Symbiosomes in the RNAi nodules varied in their uptake of SYTO9 and PI; either they resembled their normal counterpart (Fig. 5E and $\mathrm{H}$ ) or had a green ring yellow dot appearance for the uptake of both SYTO9 and PI in the interior (Fig. 5F and I). Because not a single rod-shaped rhizobia could be detected in any of the RNAi nodules examined at 10 WAI, it appeared that their differentiation into spherical symbiosomes was uninterrupted in A. hypogea CcaMK-downregulated conditions (Fig. 5E, F, H, and I).
To closely observe symbiosomes under $A$. hypogea CcaMKdownregulated conditions, ultrastructural analysis was done under scanning electron microscopy (SEM) with the controltransformed and RNAi nodules. At 4 WAI, in the control-transformed nodules, the symbiosomes were spherical and 2.5 to 3 $\mu \mathrm{m}$ in diameter (Fig. 5J, inset) and were tightly and uniformly arranged (Fig. 5J), which is similar to what we observed with wild-type nodules. In contrast, the infected cells of RNAi nodules at 10 WAI were populated with unevenly arranged pleomorphic, irregular, geometric-shaped structures such as cubes, cones, rhomboids, trapezoids, and so on (Fig. 5K). In addition, in RNAi nodules, the symbiosomes appeared to be arrested in their process of division (Fig. 5L through O). Among them, most predominant was enlarged oval structures of approximately $10 \mu \mathrm{m}$ in diameter that appeared as dyads arrested during binary fission (Fig. 5L). Other frequently detected structures in RNAi nodules were tetrads, octads, and higher-order polyad clusters which were never observed in control nodules (Fig. 5M through $\mathrm{O}$ ). The diversity of the irregular structures (Fig. 5K) that we observed in RNAi nodules could be explained by the division intermediates that we could detect (Fig. 5L through $\mathrm{O}$ ). AhCCaMK downregulation thus appears to have led to irregularities in rhizobial dissemination by affecting the division principles of the symbiosomes in the later phases of nodule development.

\section{DISCUSSION}

Whether A. hypogea, like other Aeschynomeneae and Dalbergieae legumes (Giraud et al. 2007), can establish RNS without the nod factor is not clear; however, it is evident from our investigations that $\mathrm{CCaMK}$, a member of the nod-factor-responsive Sym pathway, is expressed in A. hypogea roots and nodules (Figs. 2 and 3). Knockdown of members of the Sym pathway has been useful in elucidating their role during rhizobial invasion and nodule development (Capoen et al. 2005, 2009; Limpens et al. 2005). In a similar manner, we downregulated the expression of AhCCaMK through RNAi to catch a glimpse of the steps that are governed by this kinase during nodule development and have shown that AhCCaMK has essential roles in rhizobial dissemination and proliferation during the development of the aeschynomenoid nodules of A. hypogea (Figs. 5 and 6). Because there was a significant delay of approximately 6 weeks for the onset of nodulation in RNAi roots (Table 1), the possibility of CCaMK having a role in crack entry and cortical invasion cannot be eliminated. However, recent investigations of $S$. rostrata has revealed that intercellular invasion at lateral root bases is not dependent on CCaMK function (Capoen et al. 2009). The increase of nodules bearing nodular roots under AhCCaMK downregulated conditions was noteworthy, though the significance associated with such increase is unclear (Fig. 4; Table 1). Interestingly, these observations have some similarity with the increase of branching of nodular roots, observed under SymRK downregulated conditions in the actinorhizal plant Casuarina glauca, where the significance also remains unknown (Gherbi et al. 2008).

Downregulation of CCaMK in A. hypogea led to the generation of pockets of cells containing little or no symbiosomes in the central infected zone of its otherwise homogeneously infected aeschynomenoid nodules (Fig. 5E, F, H, and I). Rhizobial dissemination through infected cell division is a hallmark of the aeschynomenoid/lupinoid-type nodules (Alazar and Duhoux 1990; James and Sprent 1999; Klitgaard and Lavin 2005; Fedorova et al. 2007); therefore, these observations highlight the role of AhCCaMK in endosymbiont inheritance associated with infected cell division during nodule development. The presence of binucleated cells in the infected zone of 

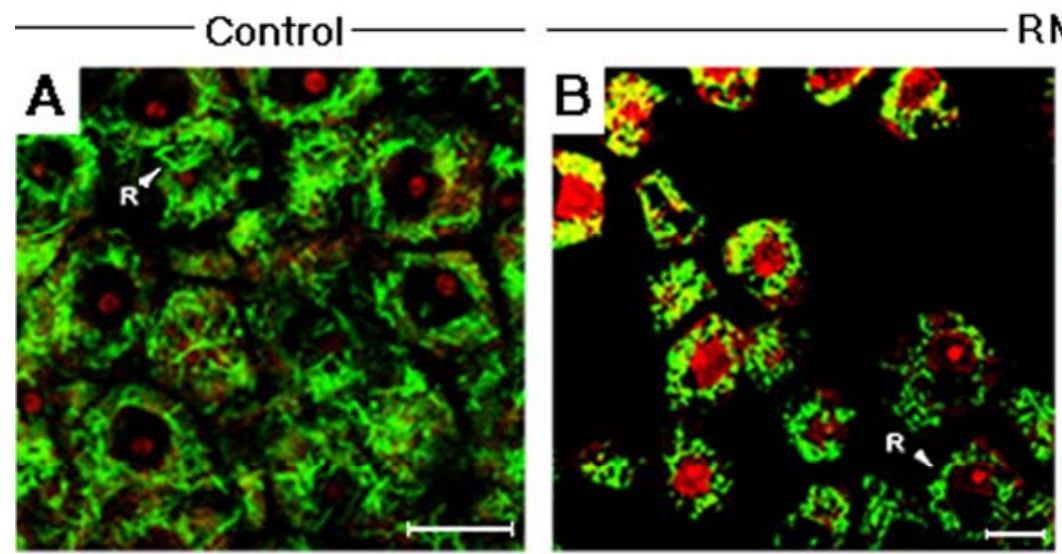

RNAi
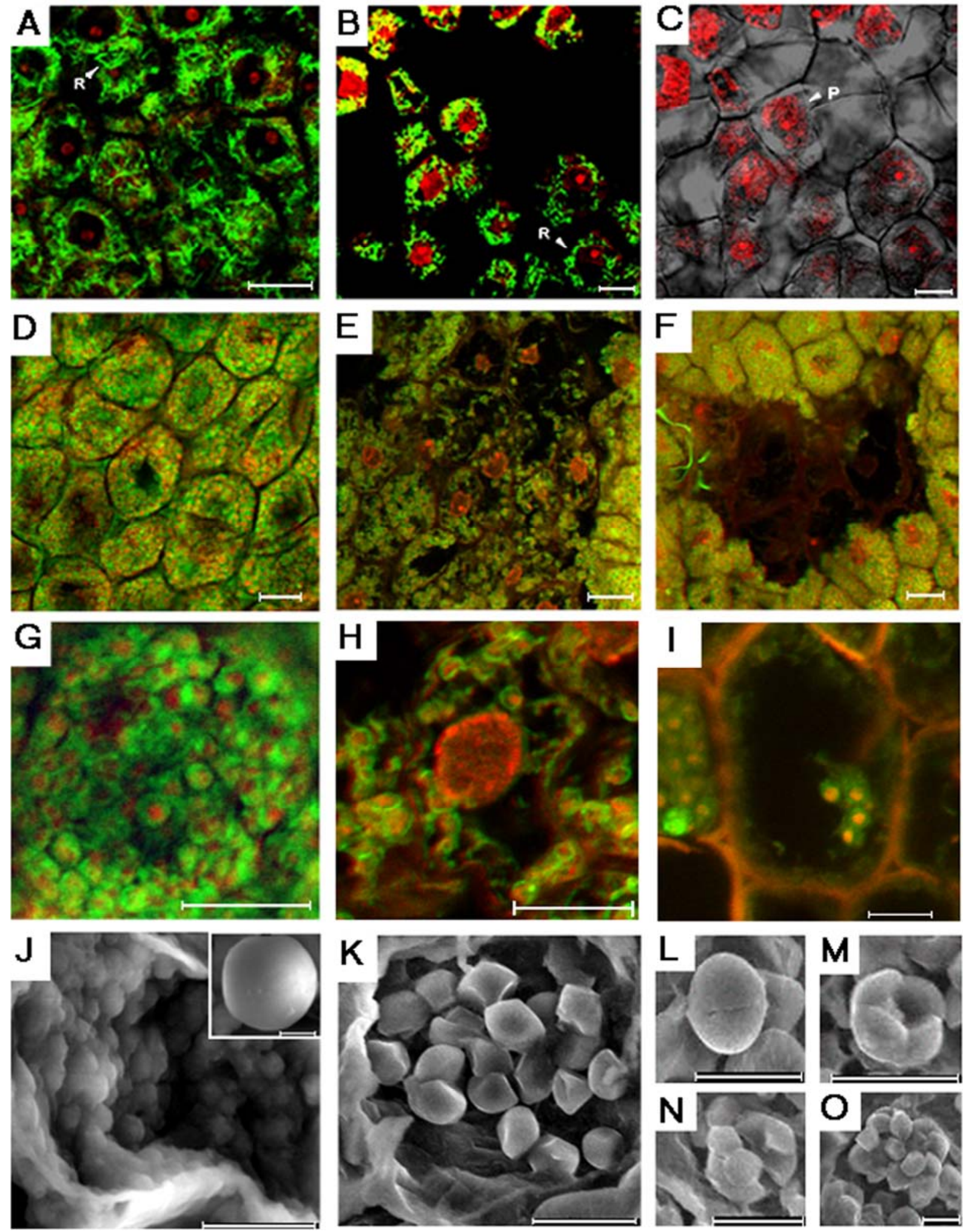

Fig. 5. Arachis hypogea $\mathrm{Ca}^{2+} /$ calmodulin-dependent protein kinase (CCaMK) knockdown phenotype in early and mature nodules. Control and RNA interference (RNAi)-transformed nodules were analyzed under confocal and scanning electron microscope. A through I, Cryosections of nodules stained with SYTO9:PI (Molecular Probes-L7007) and observed under confocal-microscope. A through C, Optical-sections of early nodules with A, rod-shaped rhizobia control-transformed at 2 weeks after inoculation (WAI); B and C, RNAi-transformed at 6 WAI. For A and B, SYTO9:PI signals are merged; in C, PI signals and bright-field image of B is merged. Arrows indicate R, rhizobia and P, perinuclear position. D through I, Optical sections of mature nodules with $\mathbf{D}$ and $\mathbf{G}$, spherical symbiosomes, control-transformed at 4 WAI; $\mathbf{E}$ and $\mathbf{H}$, RNAi-transformed at 10 WAI with pink interior and $\mathbf{F}$ and $\mathbf{I}$, with white interior. D through $\mathbf{F}$, Infected zone; $\mathbf{G}$ through $\mathbf{I}$, single infected cell. $\mathbf{J}$ through $\mathbf{O}$, Paraffin sections of mature nodules observed under scanning electron microscopy. $\mathbf{J}$, Spherical symbiosomes control-transformed at $4 \mathrm{WAI}$; J inset, a single symbiosome. K through $\mathbf{O}$, RNAi-transformed at $10 \mathrm{WAI}$. K, Irregular-shaped symbiosomes; $\mathbf{L}$ through $\mathbf{O}$, symbiosomes arrested during fission. Data presented here are representative of observations from 10 and 30 early and mature nodules, respectively. Bars: A through $\mathrm{O}, 10 \mu \mathrm{m}$; inset bar $=1 \mu \mathrm{m}$. 
the RNAi nodules (Fig. 6) also highlighted the error-prone division of the infected cells under CcaMK-downregulated conditions. These observations are consistent with earlier propositions of CCaMK having a role in mitosis and meiosis (Yang and Poovaiah 2003). During later phases of RNAi nodule development, the symbiosomes were arrested during division, indicating that, along with inheritance and dissemination in the early stages, AhCCaMK also regulates the proliferation of the endosymbiont in the later stages of nodule development. The symbiosomes appeared locked in their final stages of fission, suggesting that $\mathrm{CCaMK}$-dependent regulation is associated with the terminal steps of their division. In summary, we have been able to associate $\mathrm{CCaMK}$ with a hitherto unknown role in endosymbiont dissemination and proliferation during nodule organogenesis. It is noteworthy that CaMKIV (GI:4502557), the mammalian kinase having homology with $\mathrm{CCaMK}$, controls (PGC-1) the master regulator of mitochondrial biogenesis, suggesting that a related group of kinases are dedicated for endosymbiont proliferation and partitioning in eukaryotic cells (Wu et al. 2002).

Our results are consistent with the existing literature that illuminated the role of $\mathrm{CCaMK}$ during nodule development. Complementation of CCaMK knockout mutants of Medicago and Lotus spp. (Mtdmi3 and Ljccamk) with CCaMK from rice (OsCCaMK) or lily ( $L l \mathrm{CCaMK})$ revealed that nodule organogenesis could be completely restored in these mutants but colonization of the endosymbiont in the nodule structure was affected in both cases (Gleason et al. 2006; Godfroy et al. 2006; Chen et al. 2007; Banba et al. 2008). Although complementation of Mtdmi3 with OsCCaMK could not restore rhizobial infection in the nodule structure at all, in the case of complementation of LjCCaMk by OsCCaMK, both empty and infected nodules were generated, suggesting a lack of coordination between nodule organogenesis and rhizobial colonization (Godfroy et al. 2006; Chen et al. 2007; Banba et al. 2008). Thus, though CCaMK from nonlegumes could decode the nod-factor signal and trigger for nodule organogenesis, it was only CCaMK from legumes that could coordinate endosymbiont colonization in the developing nodule (Gleason et al. 2006; Godfroy et al. 2006; Chen et al. 2007; Banba et al. 2008). Our results, demonstrating a role for Arachis spp. CCaMK in endosymbiont dissemination and proliferation during nodule development, is consistent with the proposition of $\mathrm{CCaMK}$ from legumes having a role in endosymbiont colonization (Godfroy et al. 2006). One strong possibility is that diversification in choice of substrate had allowed this kinase to acquire its various roles in RNS in the nodulation clade. It already was demonstrated in a recent report that CYCLOPS, a substrate for CCaMK, regulates rhizobial infection whereas nodule organogenesis is predicted to be undertaken by other downstream interactions of this kinase that are yet to be identified (Capoen and Oldroyd 2008; Yano et al.

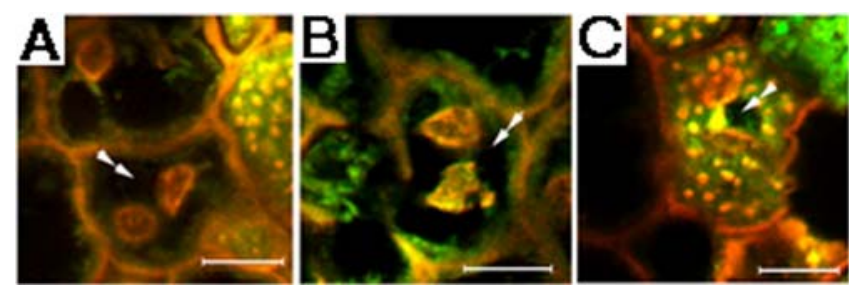

Fig. 6. Binucleated cells in Arachis hypogea $\mathrm{Ca}^{2+} /$ calmodulin-dependent protein kinase downregulated nodules. Cryosections of nodules stained with SYTO9:PI (Molecular Probes_L 27007) and observed under confocalmicroscope. A through C, Optical-sections of RNA interference-transformed mature nodules containing binucleated cells in the infected zone. Bars = $10 \mu \mathrm{m}$. Binucleated cells are indicated by double arrow.
2008). Such diversification in the choice of substrates or interacting proteins of CCaMK with the evolution of RNS can be discussed in the light of the structural alignment of homology models of CCaMK (Fig. 1C). In all CCaMK, the region between $\beta 3$ and $\alpha \mathrm{C}$ protrudes as a loop from the $\mathrm{N}$ terminal domain of the superimposed core structure of the kinase, with noticeable differences in the predicted structure between legumes and nonlegumes. A protruding loop in this position is a fingerprint feature of members of the DAPK family of kinases, where it takes an active part in physical binding of interacting proteins (Shani et al. 2004). Whether the loop in CCaMK has a similar role in the protein-protein interaction is a subject for future investigation; however, it does appear to contain the footsteps of the molecular adaptation that enabled the kinase to functionally mature into its role in RNS in the nodulating clade.

\section{MATERIALS AND METHODS}

Plant and biological materials.

A. hypogea JL-24 seed and Bradyrhizobium sp. (Arachis) NC92 were from ICRISAT, India; Agrobacterium rhizogenes R1000 from C. Somerville, Stanford University; and binary vectors from Ghent University.

\section{Cloning of Arachis hypogea CCaMK, phylogenetic} analysis, and structural alignments.

Arachis hypogea CCaMK was amplified from cDNAs prepared from roots of $A$. hypogea and cloned following standard procedures (Nag et al. 2005; Raichaudhuri et al. 2006). Primers were 5'-ATGGGATATGRWACMAGAAARCTCTC-3' and 5'TGGACGAAKAGAAGAGAGRASYAYRTCTTG-3'. For the phylogenetic analysis, protein sequences (accession number in parentheses) from A. hypogea (195542474), S. rostrata (186909461), P. sativum (71152364), M. truncatula (71152363), L. japonicus (116634228), Lilium longiflorum (71152362), Nicotiana tabacum (4741991), Petunia hybrida (148607974), Vitis vinifera (157353656), O. sativa (50511369), and Zea mays (162459834) were used. Physcomitrella patens (29289941) served as a reference to root the tree. The tree was generated by using MEGA version 4 (Tamura, Dudley, Nei, and Kumar 2007). Homology models of CCaMK kinase domains were generated based on coordinates of CaM kinase II (1a06A) using the Swiss Model Server. Structural alignment was done by using the Magic Fit option of Swiss-PdbViewer 4.0.

\section{Construct generation for in vivo studies.}

RNAi and localization constructs were generated by amplification from AhCCaMK cDNA template with primers containing restriction sites (underlined): i) ikin-primers 5'-GAAG ATCTTATGAAGTTTCAGAAATT-3' and 5'-CGCTCGAGTC AAACCGAAATCCATGA-3', ii) ivis-primers 5'-GAAGATCT TTCTTGAGAACCAAGAAACTG-3' and 5'-CGCTCGAGAG AGCTATCTCCTTGCATAGC-3', and iii) primers for localization 5'-GAAGATCTTCATGGGATATGAAACCAG-3' and 5'-CGCTCGAGTGGACGAAGAGAAGAGAGGAC-3'. Amplified fragments were cloned into pENTR4 (Invitrogen) and then into binary vectors pK7GWIWG2D(II)/pK7WGF2 by gateway technology.

\section{Transformation with Agrobacterium rhizogenes and nodulation of transgenic hairy roots.}

Transformation was done according to Sinharoy and associates (2009). Transformed and untransformed roots in the composite transgenics were differentiated from each other by the expression of the visible marker GFP. Nitrogen-fixation of 
wild-type and control- or RNAi-transformed roots bearing a similar number of nodules was assayed using nitrogenase acetylene reduction (Vessey 1994).

\section{qRT-PCR.}

Total RNA (200 ng) was reverse-transcribed by using SuperScriptII RT (Invitrogen) and oligo(dT)17. qPCR was performed by using the SYBR Green PCR Master Mix (Applied Biosystems). Arachis hypogea CCaMK primers were 5'-GCCAAAGA TGTTCAAATGGACCCT-3' and 5'-CCTGAGACTTTCAATTT CCTCTTC-3' and $A$. hypoge $a$ actin primers were 5'-GAAATGT GCCCCTTATCAGATATAC-3' and 5'-GTTTGAGAGCATAGC GTGCTGTGCTG-3'. The PCR program was 1 cycle at $95^{\circ} \mathrm{C}$ for $5 \mathrm{~min}, 40$ cycles at $95^{\circ} \mathrm{C}$ for $10 \mathrm{~s}$ and $52^{\circ} \mathrm{C}$ for $30 \mathrm{~s}$, ended by 1 cycle at $95^{\circ} \mathrm{C}$ for $1 \mathrm{~min}$. Calculations were done using the $\Delta \Delta$ cycle threshold method using $A$. hypogea actin as the endogenous control. For estimating AhCCaMK expression in different tissues of $A$. hypogea, the calibrator was expression of $\mathrm{AhCCaMK}$ in shoots where the expression was minimum, with reference to which the relative transcript abundance was calculated. For estimating transcript abundance in RNAi roots, AhCCaMK expression in control-transformed roots was used as calibrator and taken as equivalent to $100 \%$.

\section{Confocal microscopy and LVSEM.}

For confocal microscopy, sample preparation was done according to Haynes and associates (2004). Sections were prepared using cryocutter (Leica) after fixing the sample in plastic resin (Leica). Sections of 5 to $20 \mu \mathrm{m}$ were prepared and taken in poly-L-lysine-coated slides (Sigma), followed by rehydration and staining with 4',6-diamidino-2-phenylindole (DAPI) (USB) or the Live/Dead bacteria staining kit (SYTO9:PI:: 1.67:18.3 mM, Molecular Probes-L7007). For SEM, nodules were fixed with FAA (formalin, alcohol, and acetic acid) and then dehydrated by a series of alcohol gradient. They were then transferred to $100 \%$ chloroform through a gradient of alcohol/chloroform $(3: 1,1: 1,1: 3)$ mixtures. Paraplast (Sigma) was dissolved in chloroform (Merck) for embedding the tissue, then incubated at 37 and $60^{\circ} \mathrm{C}$ for $24 \mathrm{~h}$ each. Sections $(20-\mu \mathrm{m})$ were prepared using microtome (Reichert, Germany) and placed on poly-L-lysine-coated slides. Paraplast was removed with xylene and rehydrated when required. Confocal microscopy was done using a ZEISS AXIOVERT equipped with an LSM510. The settings were GFP and SYTO9 (488 nm laser, HFT405/488, NFT490, BP505-550), PI (argon $543 \mathrm{~nm}$ laser, HFT488/543, NFT545, BP560-615), and DAPI (argon $405 \mathrm{~nm}$ laser, HFT405/488, NFT490, BP420-480). SEM was done using an FEI Quanta-200 MK2 low-vacuum scanning electron microscope.

\section{ACKNOWLEDGMENTS}

We thank C. Somerville for Agrobacterium rhizogenes; S. Nigam for seed and Bradyrhizobium spp.; D. J. Chattopadhyay, A. Lohia, S. Roy Chowdhury, U. Chatterji, and B. P. Mishra for giving us access to their facilities; A. Pal and P Chakrabarti for their valuable suggestions in microscopy and structural studies; S. Ghosh for valuable comments; P. Maity, H. Patra, A. Poddar, S. Maika, S. Das, J. Saha, and S. Saha for technical support; and S. Chaudhuri and A. Raichaudhuri for their advice. Financial support was provided by University Grants Commission program UGC/191/UPE/07 and Department of Science and Technology program SR/SO/BB-24/2008. S. Sinharoy acknowledges the Council of Scientific and Industrial Research, India, for fellowship 9/28(638)2004EMR1.

\section{LITERATURE CITED}

Akasaka, Y., Mii, M., and Daimon, H. 1998. Morphological alterations and root nodule formation in Agrobacterium rhizogenes-mediated trans- genic hairy roots of peanut (Arachis hypogea L.). Ann. Bot. 81:355362.

Alazar, D., and Duhoux, E. 1990. Development of stem nodule in a tropical forage legume, Aschynomene afraspera. J. Exp. Bot. 41:1199-1206.

Ane, J. M., Kiss, G. B., Riely, B. K., Penmetsa, R. V., Oldroyd, G. E., Ayax, C., Levy, J., Debelle, F., Baek, J. M., Kalo, P., Rosenberg, C. Roe, B. A., Long, S. R., Denarie, J., and Cook, D. R. 2004. Medicago truncatula DMI1 required for bacterial and fungal symbioses in legumes. Science 303:1364-1367.

Arrighi, J. F., Barre, A., Ben Amor, B., Bersoult, A., Soriano, L. C., Mirabella, R., de Carvalho-Niebel, F., Journet, E. P., Gherardi, M., Huguet, T., Geurts, R., Denarie, J., Rouge, P., and Gough, C. 2006. The Medicago truncatula lysin [corrected] motif-receptor-like kinase gene family includes NFP and new nodule-expressed genes. Plant Physiol. 142:265-279.

Auriac, M. C., and Timmers, A. C. 2007. Nodulation studies in the model legume Medicago truncatula: Advantages of using the constitutive EF1alpha promoter and limitations in detecting fluorescent reporter proteins in nodule tissues. Mol. Plant-Microbe Interact. 20:1040-1047.

Bal, A. K., Hameed, S., and Jayaram, S. 1989. Ultrastructural characteristics of the host symbiont interface in nitrogen-fixing peanut nodules. Protoplasma 150:19-26.

Banba, M., Gutjahr, C., Miyao, A., Hirochika, H., Paszkowski, U., Kouchi, H., and Imaizumi-Anraku, H. 2008. Divergence of evolutionary ways among common sym genes: CASTOR and CCaMK show functional conservation between two symbiosis systems and constitute the root of a common signaling pathway. Plant Cell Physiol. 49:1659-1671.

Bertioli, D. J., Moretzsohn, M. C., Madsen, L. H., Sandal, N., Leal-Bertioli, S. C., Guimaraes, P. M., Hougaard, B. K., Fredslund, J., Schauser, L., Nielsen, A. M., Sato, S., Tabata, S., Cannon, S. B., and Stougaard, J. 2009. An analysis of synteny of Arachis with Lotus and Medicago sheds new light on the structure, stability and evolution of legume genomes. BMC Genomics 10:45.

Boogerd, F. C., and Rossum, D. 1997. Nodulation of groundnut by Bradyrhizobium: A simple infection process by crack entry. FEMS (Fed. Eur. Microbiol. Soc.) Microbiol. Rev 21:5-27.

Capoen, W., and Oldroyd, G. 2008. How CYCLOPS keeps an eye on plant symbiosis. Proc. Natl. Acad. Sci. U.S.A. 105:20053-20054.

Capoen, W., Goormachtig, S., De Rycke, R., Schroeyers, K., and Holsters, M. 2005. SrSymRK, a plant receptor essential for symbiosome formation. Proc. Natl. Acad. Sci. U.S.A. 102:10369-10374.

Capoen, W., Den Herder, J., Sun, J., Verplancke, C., De Keyser, A., De Rycke, R., Goormachtig, S., Oldroyd, G., and Holsters, M. 2009. Calcium spiking patterns and the role of the calcium/calmodulin-dependent kinase CCaMK in lateral root base nodulation of Sesbania rostrata. Plant Cell 21:1526-1540.

Catoira, R., Galera, C., de Billy, F., Penmetsa, R. V., Journet, E. P., Maillet, F., Rosenberg, C., Cook, D., Gough, C., and Denarie, J. 2000. Four genes of Medicago truncatula controlling components of a nod factor transduction pathway. Plant Cell 12:1647-1666.

Chandler, M. R. 1978. Some observations on infected nodules of Arachis hypogea L. by Rhizobium. J. Exp. Bot. 29:749-755.

Chen, C., Gao, M., Liu, J., and Zhu, H. 2007. Fungal symbiosis in rice requires an ortholog of a legume common symbiosis gene encoding a $\mathrm{Ca} 2+/$ calmodulin-dependent protein kinase. Plant Physiol. 145:16191628 .

Chen, C., Ane, J. M., and Zhu, H. 2008. OsIPD3, an ortholog of the Medicago truncatula DMI3 interacting protein IPD3, is required for mycorrhizal symbiosis in rice. New Phytol. 180:311-315.

Doyle, J. J., and Luckow, M. A. 2003. The rest of the iceberg. Legume diversity and evolution in a phylogenetic context. Plant Physiol. 131:900910.

Ehrhardt, D. W., Wais, R., and Long, S. R. 1996. Calcium spiking in plant root hairs responding to Rhizobium nodulation signals. Cell 85:673681.

Endre, G., Kereszt, A., Kevei, Z., Mihacea, S., Kalo, P., and Kiss, G. B. 2002. A receptor kinase gene regulating symbiotic nodule development. Nature 417:962-966.

Fedorova, E. E., de Felipe, M. R., Pueyo, J. J., and Lucas, M. M. 2007. Conformation of cytoskeletal elements during the division of infected Lupinus albus L. nodule cells. J. Exp. Bot. 58:2225-2236.

Gage, D. J. 2004. Infection and invasion of roots by symbiotic, nitrogenfixing rhizobia during nodulation of temperate legumes. Microbiol. Mol. Biol. Rev. 68:280-300.

Gherbi, H., Markmann, K., Svistoonoff, S., Estevan, J., Autran, D., Giczey, G., Auguy, F., Peret, B., Laplaze, L., Franche, C., Parniske, M., and Bogusz, D. 2008. SymRK defines a common genetic basis for plant root endosymbioses with arbuscular mycorrhiza fungi, rhizobia, and Frankiabacteria. Proc. Natl. Acad. Sci. U.S.A. 105:4928-4932.

Gillette, W. K., and Elkan, G. H. 1996. Bradyrhizobium (Arachis) sp. 
strain NC92 contains two nodD genes involved in the repression of nodA and a nolA gene required for the efficient nodulation of host plants. J. Bacteriol. 178:2757-2766.

Giraud, E., Moulin, L., Vallenet, D., Barbe, V., Cytryn, E., Avarre, J. C., Jaubert, M., Simon, D., Cartieaux, F., Prin, Y., Bena, G., Hannibal, L., Fardoux, J., Kojadinovic, M., Vuillet, L., Lajus, A., Cruveiller, S., Rouy, Z., Mangenot, S., Segurens, B., Dossat, C., Franck, W. L., Chang, W. S., Saunders, E., Bruce, D., Richardson, P., Normand, P., Dreyfus, B., Pignol, D., Stacey, G., Emerich, D., Vermeglio, A., Medigue, C., and Sadowsky, M. 2007. Legumes symbioses: Absence of Nod genes in photosynthetic bradyrhizobia. Science 316:1307-1312.

Gleason, C., Chaudhuri, S., Yang, T., Munoz, A., Poovaiah, B.W., and Oldroyd, G. E. 2006. Nodulation independent of rhizobia induced by a calcium-activated kinase lacking autoinhibition. Nature 441:1149-1152.

Godfroy, O., Debelle, F., Timmers, T., and Rosenberg, C. 2006. A rice calcium- and calmodulin-dependent protein kinase restores nodulation to a legume mutant. Mol. Plant-Microbe Interact. 19:495-501.

Goormachtig, S., Capoen, W., James, E. K., and Holsters, M. 2004. Switch from intracellular to intercellular invasion during water stress-tolerant legume nodulation. Proc. Natl. Acad. Sci. U.S.A. 101:6303-6308.

Graw, D., and Rehm, S. 1977. Vesicular arbuscular mycorrhizae in the pegs of Arachis hypogaea. J. Agron. Crop Sci. 145:75-78.

Hougaard, B. K., Madsen, L. H., Sandal, N., de Carvalho Moretzsohn, M. Fredslund, J., Schauser, L., Nielsen, A. M., Rohde, T., Sato, S., Tabata, S., Bertioli, D. J., and Stougaard, J. 2008. Legume anchor markers link syntenic regions between Phaseolus vulgaris, Lotus japonicus, Medicago truncatula and Arachis. Genetics 179:2299-2312.

Imaizumi-Anraku, H., Takeda, N., Charpentier, M., Perry, J., Miwa, H., Umehara, Y., Kouchi, H., Murakami, Y., Mulder, L., Vickers, K., Pike, J., Downie, J. A., Wang, T., Sato, S., Asamizu, E., Tabata, S., Yoshikawa, M., Murooka, Y., Wu, G.J., Kawaguchi, M., Kawasaki, S., Parniske, M. and Hayashi, M. 2005. Plastid proteins crucial for symbiotic fungal and bacterial entry into plant roots. Nature 433:527-531.

James, E. K., and Sprent, J. I. 1999. Development of N2-fixing nodules on the wetland legume Lotus uliginosus exposed to conditions of flooding. New Phytol. 142:219-231.

Kalo, P., Gleason, C., Edwards, A., Marsh, J., Mitra, R. M., Hirsch, S., Jakab, J., Sims, S., Long, S. R., Rogers, J., Kiss, G. B., Downie, J. A., and Oldroyd, G. E. 2005. Nodulation signaling in legumes requires NSP2, a member of the GRAS family of transcriptional regulators. Science 308:1786-1789.

Kanamori, N., Madsen, L. H., Radutoiu, S., Frantescu, M., Quistgaard, E. M., Miwa, H., Downie, J. A., James, E. K., Felle, H. H., Haaning, L. L., Jensen, T. H., Sato, S., Nakamura, Y., Tabata, S., Sandal, N., and Stougaard, J. 2006. A nucleoporin is required for induction of $\mathrm{Ca} 2+$ spiking in legume nodule development and essential for rhizobial and fungal symbiosis. Proc. Natl. Acad. Sci. U.S.A. 103:359-364.

Kistner, C., and Parniske, M. 2002. Evolution of signal transduction in intracellular symbiosis. Trends Plant Sci. 7:511-518.

Kistner, C., Winzer, T., Pitzschke, A., Mulder, L., Sato, S., Kaneko, T., Tabata, S., Sandal, N., Stougaard, J., Webb, K. J., Szczyglowski, K., and Parniske, M. 2005. Seven Lotus japonicus genes required for transcriptional reprogramming of the root during fungal and bacterial symbiosis. Plant Cell 17:2217-2229.

Kosuta, S., Hazledine, S., Sun, J., Miwa, H., Morris, R. J., Downie, J. A., and Oldroyd, G. E. 2008. Differential and chaotic calcium signatures in the symbiosis signaling pathway of legumes. Proc. Natl. Acad. Sci. U.S.A. 105:9823-9828.

Klitgaard, B. B., and Lavin, M. 2005. Dalbergieae s.l. Pages 307-335 in: Legumes of the World. G. P. Lewis, B. D. Schrire, M. Lock, and B. Mackinder, eds. Royal Botanic Gardens, Kew, U.K.

Levy, J., Bres, C., Geurts, R., Chalhoub, B., Kulikova, O., Duc, G., Journet, E. P., Ane, J. M., Lauber, E., Bisseling, T., Denarie, J., Rosenberg, C., and Debelle, F. 2004. A putative Ca2+ and calmodulin-dependent protein kinase required for bacterial and fungal symbioses. Science 303:1361-1364

Limpens, E., Franken, C., Smit, P., Willemse, J., Bisseling, T., and Geurts, R. 2003. LysM domain receptor kinases regulating rhizobial Nod factor-induced infection. Science 302:630-633.

Limpens, E., Mirabella, R., Fedorova, E., Franken, C., Franssen, H., Bisseling, T., and Geurts, R. 2005. Formation of organelle-like N2-fixing symbiosomes in legume root nodules is controlled by DMI2. Proc. Natl. Acad. Sci. U.S.A. 102:10375-10380.

Madsen, E. B., Madsen, L. H., Radutoiu, S., Olbryt, M., Rakwalska, M., Szczyglowski, K., Sato, S., Kaneko, T., Tabata, S., Sandal, N., and Stougaard, J. 2003. A receptor kinase gene of the LysM type is involved in legume perception of rhizobial signals. Nature 425:637-640.

Messinese, E., Mun, J. H., Yeun, L. H., Jayaraman, D., Rouge, P., Barre, A., Lougnon, G., Schornack, S., Bono, J. J., Cook, D. R., and Ane, J. M. 2007. A novel nuclear protein interacts with the symbiotic DMI3 calcium- and calmodulin-dependent protein kinase of Medicago truncatula. Mol. Plant-Microbe Interact. 20:912-921.

Middleton, P. H., Jakab, J., Penmetsa, R. V., Starker, C. G., Doll, J., Kalo, P., Prabhu, R., Marsh, J. F., Mitra, R. M., Kereszt, A., Dudas, B., VandenBosch, K., Long, S. R., Cook, D. R., Kiss, G. B., and Oldroyd, G. E. 2007. An ERF transcription factor in Medicago truncatula that is essential for Nod factor signal transduction. Plant Cell 19:1221-1234.

Mitra, R. M., Gleason, C. A., Edwards, A., Hadfield, J., Downie, J. A., Oldroyd, G. E., and Long, S. R. 2004. A Ca2+/calmodulin-dependent protein kinase required for symbiotic nodule development: Gene identification by transcript-based cloning. Proc. Natl. Acad. Sci. U.S.A. 101:4701-4705.

Nag, R., Maity, M. K., and Dasgupta, M. 2005. Dual DNA binding property of $\mathrm{ABA}$ insensitive 3 like factors targeted to promoters responsive to ABA and auxin. Plant Mol. Biol. 59:821-838.

Oldroyd, G. E., and Downie, J. A. 2004. Calcium, kinases and nodulation signalling in legumes. Nat. Rev. Mol. Cell Biol. 5:566-576.

Oldroyd, G. E., and Downie, J. A. 2008. Coordinating nodule morphogenesis with rhizobial infection in legumes. Annu. Rev. Plant Biol. 59:519-546.

Partida-Martinez, L. P., and Hertweck, C. 2005. Pathogenic fungus harbours endosymbiotic bacteria for toxin production. Nature 437:884888.

Radutoiu, S., Madsen, L. H., Madsen, E. B., Felle, H. H., Umehara, Y., Gronlund, M., Sato, S., Nakamura, Y., Tabata, S., Sandal, N., and Stougaard, J. 2003. Plant recognition of symbiotic bacteria requires two LysM receptor-like kinases. Nature 425:585-592.

Raichaudhuri, A., Bhattacharyya, R., Chaudhuri, S., Chakrabarti, P., and Dasgupta, M. 2006. Domain analysis of a groundnut calcium-dependent protein kinase: Nuclear localization sequence in the junction domain is coupled with nonconsensus calcium binding domains. J. Biol. Chem. 281:10399-10409.

Saito, K., Yoshikawa, M., Yano, K., Miwa, H., Uchida, H., Asamizu, E., Sato, S., Tabata, S., Imaizumi-Anraku, H., Umehara, Y., Kouchi, H., Murooka, Y., Szczyglowski, K., Downie, J.A., Parniske, M., Hayashi, M., and Kawaguchi, M. 2007. NUCLEOPORIN85 is required for calcium spiking, fungal and bacterial symbioses, and seed production in Lotus japonicus. Plant Cell 19:610-624.

Schauser, L., Roussis, A., Stiller, J., and Stougaard, J. 1999. A plant regulator controlling development of symbiotic root nodules. Nature 402:191-195.

Sen, D., Weaver, R. W., and Bal, A. K. 1986. Structure and organisation of effective peanut and cowpea root nodules induced by rhizobial strain 32H1. J. Exp. Bot. 37:356-363.

Shani, G., Marash, L., Gozuacik, D., Bialik, S., Teitelbaum, L., Shohat, G., and Kimchi, A. 2004. Death-associated protein kinase phosphorylates ZIP kinase, forming a unique kinase hierarchy to activate its cell death functions. Mol. Cell Biol. 24:8611-8626.

Sinharoy, S., Saha, S., Chaudhury, S. R., and Dasgupta, M. 2009. Transformed hairy roots of Arachis hypogea: A tool for studying root nodule symbiosis in a non-infection thread legume of the Aeschynomeneae tribe. Mol. Plant-Microbe Interact. 22:132-142.

Smit, P., Raedts, J., Portyanko, V., Debelle, F., Gough, C., Bisseling, T., and Geurts, R. 2005. NSP1 of the GRAS protein family is essential for rhizobial Nod factor-induced transcription. Science 308:1789-1791.

Smit, P., Limpens, E., Geurts, R., Fedorova, E., Dolgikh, E., Gough, C., and Bisseling, T. 2007. Medicago LYK3, an entry receptor in rhizobial nodulation factor signaling. Plant Physiol. 145:183-191.

Sprent, J. I. 2007. Evolving ideas of legume evolution and diversity: A taxonomic perspective on the occurrence of nodulation. New Phytol. 174:11-25.

Stracke, S., Kistner, C., Yoshida, S., Mulder, L., Sato, S., Kaneko, T., Tabata, S., Sandal, N., Stougaard, J., Szczyglowski, K., and Parniske, M. 2002. A plant receptor-like kinase required for both bacterial and fungal symbiosis. Nature 417:959-962.

Taurian, T., Moron, B., Soria-Diaz, M. E., Angelini, J. G., Tejero-Mateo, P., Gil-Serrano, A., Megias, M., and Fabra, A. 2008. Signal molecules in the peanut-bradyrhizobia interaction. Arch. Microbiol. 189:345356.

Tereshko, V., Teplova, M., Brunzelle, J., Watterson, D. M., and Egli, M. 2001. Crystal structures of the catalytic domain of human protein kinase associated with apoptosis and tumor suppression. Nat. Struct. Biol. 8:899-907.

Tirichine, L., Imaizumi-Anraku, H., Yoshida, S., Murakami, Y., Madsen, L. H., Miwa, H., Nakagawa, T., Sandal, N., Albrektsen, A. S., Kawaguchi, M., Downie, A., Sato, S., Tabata, S., Kouchi, H., Parniske, M., Kawasaki, S., and Stougaard, J. 2006a. Deregulation of a Ca2+/calmodulin-dependent kinase leads to spontaneous nodule development. Nature 441:1153-1156. 
Tirichine, L., James, E. K., Sandal, N., and Stougaard, J. 2006b. Spontaneous root-nodule formation in the model legume Lotus japonicus: A novel class of mutants nodulates in the absence of rhizobia. Mol. PlantMicrobe Interact. 19:373-382.

Veereshlingam, H., Haynes, J. G., Penmetsa, R. V., Cook, D. R., Sherrier, D. J., and Dickstein, R. 2004. nip, a symbiotic Medicago truncatula mutant that forms root nodules with aberrant infection threads and plant defense-like response. Plant Physiol. 136:3692-3702.

Vessey, J. K. 1994. Measurement of nitrogenase activity in legume root nodules: In defence of the acetylene reduction assay. Plant Soil 158:151-162.

Wais, R. J., Galera, C., Oldroyd, G., Catoira, R., Penmetsa, R. V., Cook, D., Gough, C., Denarie, J., and Long, S. R. 2000. Genetic analysis of calcium spiking responses in nodulation mutants of Medicago truncatula. Proc. Natl. Acad. Sci. U.S.A. 97:13407-13412.

Wu, H., Kanatous, S. B., Thurmond, F. A., Gallardo, T., Isotani, E., BasselDuby, R., and Williams, R. S. 2002. Regulation of mitochondrial biogenesis in skeletal muscle by CaMK. Science 296:349-352.

Yang, T., and Poovaiah, B. W. 2003. Calcium/calmodulin-mediated signal network in plants. Trends Plant Sci. 8:505-512.

Yano, K., Yoshida, S., Muller, J., Singh, S., Banba, M., Vickers, K. Markmann, K., White, C., Schuller, B., Sato, S., Asamizu, E., Tabata, S., Murooka, Y., Perry, J., Wang, T. L., Kawaguchi, M., ImaizumiAnraku, H., Hayashi, M., and Parniske, M. 2008. CYCLOPS, a mediator of symbiotic intracellular accommodation. Proc. Natl. Acad. Sci. U.S.A. 105:20540-20545. 